\title{
Acinetobacter baumannii quorum-sensing signalling molecule induces the expression of drug-resistance genes
}

\author{
YI DOU $^{1}$, FEI SONG ${ }^{1}$, FENG GUO $^{1}$, ZENGDING ZHOU $^{1}$, CAILIAN ZHU $^{2}$, JUN XIANG $^{1}$ and JINGNING HUAN ${ }^{1}$ \\ ${ }^{1}$ Department of Burns and Plastic Surgery, Ruijin Hospital, Shanghai Jiaotong University School of Medicine, \\ Shanghai 200025; ${ }^{2}$ The Ninth People's Hospital, School of Stomatology, Shanghai Jiaotong University, \\ Shanghai Research Institute of Stomatology, Shanghai 200011, P.R. China
}

Received January 14, 2016; Accepted March 13, 2017

DOI: $10.3892 / \mathrm{mmr} .2017 .6528$

\begin{abstract}
Quorum-sensing signalling molecules such as $\mathrm{N}$-acyl homoserine lactones (AHLs) enable certain Gram-negative bacteria to respond to environmental changes through behaviours, such as biofilm formation and flagellar movement. The present study aimed to identify Acinetobacter baumannii AHLs and assess their influence on antibiotic resistance. A clinical isolate of A. baumannii strain $\mathrm{S}(\mathrm{AbS})$ was collected from the wound of a burn patient and high-performance liquid chromatography and tandem quadrupole or quadrupole time-of-flight high-resolution mass spectrometry was used to identify AbS AHLs. Antibiotic sensitivity was assessed in an AHL-deficient AbS mutant $(\mathrm{AbS}-\mathrm{M})$, and the expression of drug-resistance genes in the presence of meropenem in $\mathrm{AbS}, \mathrm{AbS}-\mathrm{M}$ and $\mathrm{AbS}-\mathrm{M}$ treated with the AHL N-3-hydroxy-dodecanoyl-homoserine lactone (N-3-OH-C ${ }_{12}-\mathrm{HSL}$ ). AbS-M was more sensitive to meropenem and piperacillin than wild-type $\mathrm{AbS}$, but resistance was restored by supplementation with $\mathrm{N}-3-\mathrm{OH}-\mathrm{C}_{12}-\mathrm{HSL}$. In addition, meropenem-treated $\mathrm{AbS}-\mathrm{M}$ expressed lower levels of the drug-resistance genes oxacillinase 51, AmpC, AdeA and AdeB; treatment with $\mathrm{N}-3-\mathrm{OH}-\mathrm{C}_{12}-\mathrm{HSL}$ also restored the expression of these genes. Overall, the results of the present study indicate that $\mathrm{N}-3-\mathrm{OH}-\mathrm{C}_{12}-\mathrm{HSL}$ may be involved in regulating the expression of drug-resistance genes in A. baumannii. Therefore, this quorum-sensing signalling molecule may be an important target for treating multidrug-resistant A. baumannii infections.
\end{abstract}

Correspondence to: Dr Jingning Huan, Department of Burns and Plastic Surgery, Ruijin Hospital, Shanghai Jiaotong University School of Medicine, 197 Ruijin Er Road, Huangpu, Shanghai 200025, P.R. China

E-mail: huanjn194@sina.com

Key words: N-acyl homoserine lactone, Acinetobacter baumannii, quorum sensing, multidrug-resistance genes

\section{Introduction}

Staphylococcus aureus and Pseudomonas aeruginosa are the main bacteria that opportunistically infect patients with burns (1). However, recent reports (2-5) indicate that the proportion of infections caused by Acinetobacter baumannii is gradually increasing and, in some instances, already exceeds the number of infections caused by $P$. aeruginosa. A. baumannii is the most commonly detected Gram-negative organism infecting patients with burns (2-5). However, the emergence of multidrug-resistant $A$. baumannii complicates the clinical treatment of these infections (6-8).

Quorum sensing is a form of cell-cell communication that bacteria use to coordinate the expression of genes involved in certain behaviours, such as flagellar movement $(9,10)$, virulence factor production $(11,12)$, and secondary metabolite and biofilm production $(9,13)$. Various quorum-sensing signalling molecules have been identified, including oligopeptides in Gram-positive bacteria and N-acyl homoserine lactones (AHLs) in some Gram-negative bacteria (14). Acinetobacter spp. also produce AHLs that possess quorum-sensing activity (15), and the A. baumannii AHL, N-3-hydroxy-dodecanoyl-homoserine lactone (N-3-OH- $\left.\mathrm{C}_{12}-\mathrm{HSL}\right)$, is known to affect its motility and biofilm formation $(16,17)$.

Since quorum sensing allows bacteria to respond to environmental changes as a colony and thereby boosts survival, disrupting the quorum-sensing system may be a promising new strategy for the treatment of infections (18-20). It is important to investigate novel strategies for the inhibition of A. baumannii by targeting AHLs $(16,17,21-23)$, but little is currently known about the types and functions of AHLs produced by A. baumannii.

All AHLs share a common homoserine moiety but can contain acyl side-chains of various lengths and degrees of saturation and with various groups at the third carbon position. AHLs generate characteristic fragment ions on electrospray ionization (ESI) at a mass-to-charge ratio $(\mathrm{m} / \mathrm{z})$ of 102 , and the acyl side-chains generate the corresponding fragment ions at $m / z[\mathrm{M}+\mathrm{H}-101]^{+}(15,24-33)$.

The most common methods for identifying AHLs involve a combination of thin-layer chromatography and biosensors $(34,35)$. These methods are simple and inexpensive but are limited by the sensitivity of the biosensor and the use of 
standard substances as references. In the present study, a clinical isolate of A. baumannii strain $\mathrm{S}(\mathrm{AbS})$ was collected from the wound of a burn patient and cultured. AHLs produced by $\mathrm{AbS}$ were subsequently analysed by high-performance liquid chromatography (HPLC) and either tandem quadrupole (TQ) or quadrupole time-of-flight (Q-TOF) high-resolution mass spectrometry (HRMS). The present study adds to the growing body of research on the quorum-sensing system of A. baumannii and may contribute to the development of novel antibacterial therapies that target AHLs for treating multidrug-resistant A. baumannii infection.

\section{Materials and methods}

Bacterial strains and growth conditions. A single nosocomial specimen of $\mathrm{AbS}$ was collected from the wound surface exudates of a patient admitted to the Department of Burns and Plastic Surgery at Ruijin Hospital (Shanghai Jiaotong University School of Medicine, Shanghai, China) in 2008. Antibiotic sensitivity was assessed according to the guidelines provided by the Clinical and Laboratory Standards Institute (CLSI) (36), which included using ATB test strips (BioMérieux, Marcy l'Etoile, France) and the Kirby-Bauer disk diffusion method with antibiotic discs from Oxoid, Ltd. (Thermo Fisher Scientific, Inc., Waltham, MA, USA). Agrobacterium tumefaciens strain KYC55 was used as a biosensor, and was kindly provided by Professor Jun Zhu (College of Life Sciences, Nanjing Agricultural University, Nanjing, China). A. baumannii was cultured statically in Luria-Bertani (LB) medium or Mueller-Hinton (MH) medium (Oxoid, Basingstoke, UK) at $37^{\circ} \mathrm{C}$; A.tumefaciens KYC55 was cultured statically in LB medium at $28^{\circ} \mathrm{C}$.

Preparation of AHL extract. A. baumannii and A.tumefaciens were stored at $-80^{\circ} \mathrm{C}$ in bacteria stock solution (Beyotime Biotechnology, Shanghai, China). A. baumannii were inoculated on LB agarose plates and incubated overnight at $37^{\circ} \mathrm{C}$. Individual colonies $\left(1 \times 10^{8}\right.$ colony-forming units $\left.(\mathrm{CFU}) / \mathrm{ml}\right)$ were selected and cultured in $15 \mathrm{ml} \mathrm{LB}$ medium at $37^{\circ} \mathrm{C}$.

For HPLC-MS, bacteria were cultured in $500 \mathrm{ml} \mathrm{LB}$ medium from the overnight LB agarose plates, and $500 \mathrm{ml}$ bacterial liquid was collected at $8 \mathrm{~h}$, as determined by the AHL activity curve. Bacterial samples were centrifuged $(4,500 \times \mathrm{g}$ for $20 \mathrm{~min}$ ) and supernatants were passed through a $0.22 \mu \mathrm{m}$ filter. An equal volume of $100 \%$ ethyl acetate was added to the filtrate, and the ethyl acetate phase was collected for AHL extraction and dried in a vacuum centrifuge. The residue was the AHL extract and was then re-dissolved in $50 \mu 1$ ethyl acetate.

Analysis of AHL activity. AHL activity was measured at 4 , $8,16,24,32,40$ and $48 \mathrm{~h}$ after seeding. At each time point, 3 bacterial liquid were collected and the optical density (OD) 600 was measured. AHL extracts in $50 \mu$ l ethyl acetate from 4, 8, 16, 24, 32, 40 and $48 \mathrm{~h}$ were added to cultures of A. tumefaciens KYC55 cultures, and $\beta$-galactosidase activity was measured to indirectly indicate AHL activity, as described previously $(15,37)$. Following overnight incubation, the $\mathrm{OD}_{600}$ was measured and $0.8 \mathrm{ml} \mathrm{Z}$ buffer (in each litre containing: $16.1 \mathrm{~g}\left(\mathrm{Na}_{2} \mathrm{HPO}_{4}\right) 7 \mathrm{H}_{2} \mathrm{O}, 5.5 \mathrm{~g}\left(\mathrm{NaH}_{2} \mathrm{PO}_{4}\right) \mathrm{H}_{2} \mathrm{O}, 0.75 \mathrm{~g} \mathrm{KCl}$,
$0.245 \mathrm{~g}\left(\mathrm{MgSO}_{4}\right) 7 \mathrm{H}_{2} \mathrm{O}, 2.7 \mathrm{ml}$ 2-mercaptoethanol, adjusted to $\mathrm{pH} 7.0$ with $\mathrm{HCl}), 10 \mu 10.05 \%$ sodium dodecyl sulphate, $15 \mu \mathrm{l}$ chloroform and $0.1 \mathrm{ml}$ ortho-nitrophenyl- $\beta$-galactoside (4 mg/ml) were added, with a final sample volume of $0.2 \mathrm{ml}$. The time (T) taken for the solution to turn yellow was recorded, and $0.6 \mathrm{ml} 1 \mathrm{M} \mathrm{Na}_{2} \mathrm{CO}_{3}$ was added to terminate the reaction. The $\mathrm{OD}_{420}$ of supernatants was determined, and relative AHL activity was calculated as follows: Activity in Miller units $=\left(1,000 \times \mathrm{OD}_{420}\right) /\left(\mathrm{OD}_{600} \times \mathrm{Tx} 0.2\right)$.

Identification of AHLs using HPLC-MS. AHLs of different structures contain the same homoserine lactone (HSL) ring, and this moiety generates characteristic fragment ions at $m / z, 102$ (25). Based on this principle, AbS AHLs were identified by HPLC combined with either TQ or Q-TOF HRMS using a 1200 HPLC-6140 TQ MS or a 1260 HPLC-6538 Q-TOF HRMS (Agilent Technologies, Inc., Santa Clara, CA, USA), respectively. Resultant chromatograms were compared with those of standard substances to elucidate the structure of AbS AHLs. The test conditions were as follows: An Agilent Poroshell 120 SB-C18 chromatographic column $(2.7 \mu \mathrm{m}$, 2.1x100 mm; Agilent Technologies, Inc.) was used with acetonitrile and water as the mobile phase. The initial acetonitrile concentration was $40 \%$, which was increased to $100 \%$ after $30 \mathrm{~min}$, with a $\mathrm{z}$-flow rate of $0.3 \mathrm{ml} / \mathrm{min}$ and sample injection volume of $10 \mu \mathrm{l}$. Positive-ion ESI was conducted with the ion source at $350^{\circ} \mathrm{C}$. The dry $\mathrm{N}_{2}$ flow rate was $8 \mathrm{l} / \mathrm{min}$, and the air pressure of atomizing $\mathrm{N}_{2}$ was 40 psi. The capillary voltage was 4,000 V. HPLC-TQ HRMS was performed with a precursor ion scan and daughter ion scan (collision energy, 15-30 units), while HPLC-Q-TOF HRMS involved MS1 and MS2 full scans (collision energy, 15-30 units).

Establishment of an AHL-deficient AbS mutant (AbS-M). An $\mathrm{AbS}$ mutant that is unable to produce AHLs was established using pKNG101.abaI::Km, as previously described (38); the pKNG101.abaI::Km plasmid was provided by Professor Philip N. Rather (Department of Microbiology and Immunology, Emory University School of Medicine, Atlanta, GA, USA). This vector was transformed into Escherichia coli strain SM10, and the resultant SM10/pKNG101.abaI::Km was cultured with AbS in a filter-mating system in $\mathrm{LB}$ medium at $37^{\circ} \mathrm{C}$ without antibiotics for $24 \mathrm{~h}$, after which it was cultured and screened on LB agarose plates containing $10 \%$ sucrose without $\mathrm{NaCl}$. Sucrose resistance indicates that the bacteria have lost the integrated pKNG101 plasmid and therefore streptomycin sensitivity. $\mathrm{AbS}-\mathrm{M}$ was screened for kanamycin resistance, and Southern blotting was used to confirm that colonies with this phenotype had abaI::Km disruption, as previously described (38).

Antibacterial sensitivity of $A b S$ and $A b S-M$. The minimum inhibitory concentration (MIC) of common antibacterial drugs (including, meropenem, piperacillin, ceftazidime, ciprofloxacin, sulfamethoxazole/trimethoprim and minocycline) against $\mathrm{AbS}, \mathrm{AbS}-\mathrm{M}$ and $\mathrm{AbS}-\mathrm{M}$ supplemented with $10 \mu \mathrm{mol}$ N-3-OH-C 12 -HSL (AbS-M+HSL; \#53727; Sigma-Aldrich; Merck KGaA, Darmstadt, Germany) was assessed using the broth-micro-dilution method, according to the CLSI protocol. Briefly, overnight bacterial cultures were inoculated at $5 \times 10^{5} \mathrm{CFU} / \mathrm{ml}$ in $1 \mathrm{ml} \mathrm{MH}$ medium containing 
Table I. Primer sequences used for quantitative polymerase chain reaction.

\begin{tabular}{|c|c|c|}
\hline Gene & Primer sequence $\left(5^{\prime}-3^{\prime}\right)$ & Product length (bp) \\
\hline 16S rRNA & $\begin{array}{l}\text { F: ACGGTCGCAAGACTAAAACTCA } \\
\text { R: GTATGTCAAGGCCAGGTAAGGT }\end{array}$ & 108 \\
\hline$O X A-51$ & $\begin{array}{l}\text { F: CTATGGTAATGATCTTGCTCGTG } \\
\text { R: TGGTGGTTGCCTTATGGTG }\end{array}$ & 104 \\
\hline$A m p C$ & $\begin{array}{l}\text { F: TTATGCGGGCAATACACCA } \\
\text { R: CTGACAGAACCTAGCTCAAAAATG }\end{array}$ & 207 \\
\hline$O X A-23$ & $\begin{array}{l}\text { F: AAGGGCGAGAAAAGGTCATT } \\
\text { R: TCCTGATAGACTGGGACTGCA }\end{array}$ & 89 \\
\hline$I M P-4$ & $\begin{array}{l}\text { F: ATTCTCAATCCATCCCCACG } \\
\text { R: CCTTTCAGGCAGCCAAACTAC }\end{array}$ & 185 \\
\hline$V I M-2$ & $\begin{array}{l}\text { F: AACTCTTCTATCCTGGTGCTGC } \\
\text { R: TGCGTGACAACTCATAAATCG }\end{array}$ & 105 \\
\hline AdeA & $\begin{array}{l}\text { F: AGTCGGAGGTATCATTGAAAAGG } \\
\text { R: TGAACTTTGAGTCTTGCCACCT }\end{array}$ & 162 \\
\hline$A d e B$ & $\begin{array}{l}\text { F: ATGCGTGAAATGGAACAACTG } \\
\text { R: CCAAGACAAGGAAGACAACTAACA }\end{array}$ & 145 \\
\hline AdeC & $\begin{array}{l}\text { F: GCCATTCAATCAGCTTTTCGT } \\
\text { R: GAGTTTATAGGTTGCAGCAGTCG }\end{array}$ & 117 \\
\hline GAPDH & $\begin{array}{l}\text { F: ACCACAGTCCATGCCATCAC } \\
\text { R: TCCACCACCCTGTTGCTGTA }\end{array}$ & 440 \\
\hline
\end{tabular}

bp, base pair; $O X A$, oxacillinase; F, forward; R, reverse; AmpC, AmpC type $\beta$-lactamase; IMP, IMP type metallo- $\beta$-lactamase; VIM, verona integron-mediated metallo- $\beta$-lactamase; Ade, Acinetobacter drug efflux; GAPDH, glyceraldehyde-3-phosphate dehydrogenase.

a range of concentrations $(128,64,32,16,8,4,2,1,0.5,0.25$, $0.125,0.0625,0.03125$ and $0 \mu \mathrm{g} / \mathrm{ml})$ of the antibacterial drugs. Following $24 \mathrm{~h}$ incubation at $37^{\circ} \mathrm{C}$, the MIC against bacterial growth was assessed by visual examination. Each antibiotic concentration was tested three times.

Expression of drug-resistance genes in $A b S, A b S-M$ and AbS-M+HSL treated with $0.125 \mu \mathrm{g} / \mathrm{ml}$ meropenem or $\mathrm{AbS}$ untreated with meropenem (AbS-U) for $24 \mathrm{~h}$. A total of $45 \mu 10.5$ McFarland bacterial liquid (AbS, AbS-M and AbS-M+AHL) was added to $3 \mathrm{ml} \mathrm{LB}$ medium containing $0.125 \mu \mathrm{g} / \mathrm{ml}$ meropenem, with a final concentration of $10 \mu \mathrm{M}$ AHL (N-3-OH-C $\left.{ }_{12}-\mathrm{HSL}\right)$. Alternatively, $45 \mu \mathrm{l} 0.5 \mathrm{McF}$ arland bacterial liquid was added into $3 \mathrm{ml} \mathrm{LB}$ medium without meropenem (AbS-U). The cultures were incubated at $37^{\circ} \mathrm{C}$. After 24 h, $1 \mathrm{ml}$ bacterial liquid was centrifuged $(10,621 \mathrm{x} \mathrm{g}$ for $1 \mathrm{~min}$ ) and supernatants were discarded. Total RNA was extracted using TRIzol Reagent (Invitrogen; Thermo Fisher Scientific, Inc., Waltham, MA, USA), according to the manufacturer's protocol; concentration and purity were determined using an ultraviolet spectrophotometer. RNA was reverse transcribed into cDNA using the AMV First Strand cDNA Synthesis kit (New England Biolabs, Inc., Ipswich, MA, USA), according to the manufacturer's protocol. AbS-U, $\mathrm{AbS}, \mathrm{AbS}-\mathrm{M}$ and $\mathrm{AbS}-\mathrm{M}+\mathrm{HSL}$ cultures were incubated for $24 \mathrm{~h}$ and the expression levels of 16S rRNA, Oxacillinase $(O X A)-51$, AmpC type $\beta$-lactamase $(A m p C)$, oxacillinase (OXA)-23, IMP type metallo- $\beta$-lactamase $(I M P)-4$, verona integron-mediated metallo- $\beta$-lactamase (VIM)-2,
Acinetobacter drug efflux (Ade) $A, A d e B$ and $A d e C$ were assessed by quantitative polymerase chain reaction (qPCR) using a StepOnePlus Real-Time PCR System (Applied Biosystems; Thermo Fisher Scientific, Inc.) and SYBR-Green Master Mix (Thermo Fisher Scientific, Inc.); primers used are listed in Table I. Glyceraldehyde-3-phosphate dehydrogenase (GAPDH) expression was measured as a reference, and gene expressions were calculated in terms of fold change using the comparative $\mathrm{Cq}$ method; relative mRNA expression was calculated using the $2^{-\Delta \Delta \mathrm{Cq}}$ method (39). The experiments were repeated 3 times.

Statistical analyses. Data were presented as the mean \pm standard deviation and analysed using Student's t-test, analysis of variance and least significant difference pot hoc test with SPSS version 19.0 (IBM SPSS, Armonk, NY, USA). P<0.05 was considered to indicate a statistically significant difference.

\section{Results}

Changes in AHL activity of AbS. AbS growth rate and AHL activity were measured periodically between 4 and $48 \mathrm{~h}$ incubation (Fig. 1). AHL activity increased from 5.00 \pm 1.00 Miller units at $4 \mathrm{~h}$ culture to a maximum of $279.33 \pm 27.59$ Miller units at $8 \mathrm{~h}$. Subsequently, the activity decreased to $28.67 \pm 4.16$ Miller units at $16 \mathrm{~h}$ and plateaued. The AbS growth curve did not correlate with AHL activity after bacterial growth reached the log phase; the $\mathrm{OD}_{600}$ (bacterial growth) peaked at $0.90 \pm 0.01$ after $24 \mathrm{~h}$ of culture and then plateaued. 


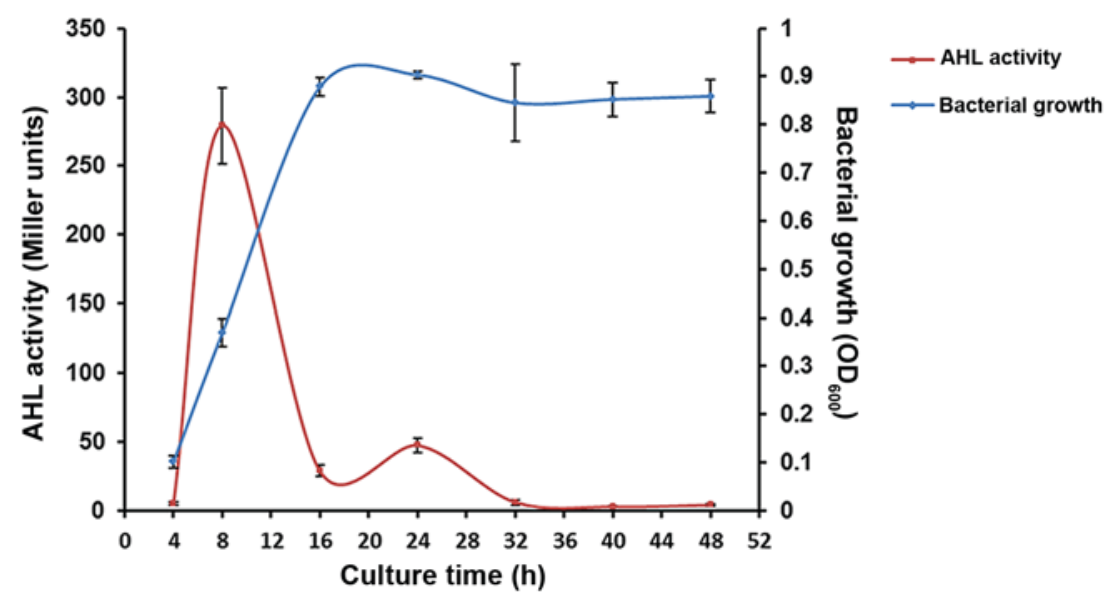

Figure 1. Acinetobacter baumannii strain S growth curve and corresponding measurements of AHL activity. AHL, N-acyl homoserine lactone; OD, optical density.

AHLs produced by AbS. AHLs that were extracted from AbS culture supernatants using ethyl acetate were screened using HPLC-TQ MS. As presented in Fig. 2, the precursor ion scan at $\mathrm{m} / \mathrm{z}, 102$ detected 30 precursor ions, including those at $\mathrm{m} / \mathrm{z} 282$, 284 and 300 (each precursor ion represents one compound). MS2 spectrum analysis of these 30 ions confirmed that they could generate fragment ions at $\mathrm{m} / \mathrm{z} 102$, suggesting that they may be AHLs.

In the positive ionization mode of ESI, extracted AHLs generated a quasi-molecular ion at $\mathrm{m} / \mathrm{z}, 300$ and major fragment ions at $\mathrm{m} / \mathrm{z}, 102$ and $\mathrm{m} / \mathrm{z} 74$ (Fig. 3A). The ion at $\mathrm{m} / \mathrm{z}, 102$ was the most abundant, and in order to determine its structure, HPLC-Q-TOF HRMS was used to examine the elemental composition of this ion and related daughter fragment ions. The elemental composition at $\mathrm{m} / z, 300$ was $\mathrm{C}_{16} \mathrm{H}_{30} \mathrm{NO}_{4}$, representing the $[\mathrm{M}+\mathrm{H}]{ }^{+}$ions of $\mathrm{N}-3-\mathrm{OH}-\mathrm{C}_{12}-\mathrm{HSL}$. The two major fragment ions were $\mathrm{C}_{4} \mathrm{H}_{8} \mathrm{NO}(\mathrm{m} / z, 102)$ and $\mathrm{C}_{3} \mathrm{H}_{8} \mathrm{NO}$ $(\mathrm{m} / \mathrm{z}, 74)$, both of which were derived from the HSL ring of $\mathrm{N}-3-\mathrm{OH}-\mathrm{C}_{12}-\mathrm{HSL}$, which was the only AHL molecule identified (Fig. 3B). The major fragmentation pathway is shown in Fig. 4. In addition, some low-abundance ions were detected in the MS2 spectrum $(\mathrm{m} / \mathrm{z}, 121,97$ and 83), and they contained only two elements, $\mathrm{H}$ and $\mathrm{C}$. We hypothesized that these were derived from the fragmentation of carbon chains near the acyl group.

Since components from the culture media may interfere with AHL detection, HPLC-Q-TOF HRMS and tandem MS were used to scan for AHL molecules identified in previous screens. The present study also determined the elemental compositions of the 30 precursor ions and their corresponding daughter ions at $m / z, 102$. The results revealed that only ions detected at $\mathrm{m} / \mathrm{z}, 300 \geq 102$ met the structural requirement for AHLs. The daughter ions at $\mathrm{m} / \mathrm{z}, 102$ were derived from 29 candidate molecules that contained $\mathrm{C}_{5} \mathrm{H}_{12} \mathrm{NO}$ and therefore could not be AHLs.

According to the composition and degree of unsaturation, the signal molecule at $\mathrm{m} / \mathrm{z}, 300$ was inferred to be $\mathrm{N}-3-\mathrm{OH}-\mathrm{C}_{12}-\mathrm{HSL}$. HPLC-MS was then used to examine a commercially available $\mathrm{N}-3-\mathrm{OH}-\mathrm{C}_{12}-\mathrm{HSL}$, and the results confirmed that it was structurally identical to the $\mathrm{N}-3-\mathrm{OH}-\mathrm{C}_{12}$ - $\mathrm{HSL}$ detected in the present study.

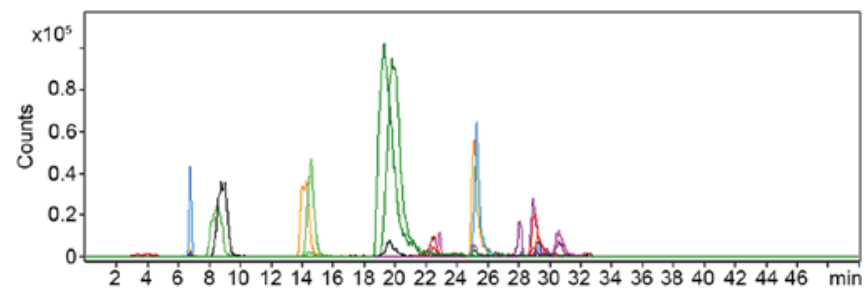

Figure 2. Ion chromatogram of the Acinetobacter baumannii strain S culture medium extract. A total of 30 precursor ions that could generate daughter ions at a mass-to-charge ratio of 102 were detected.

A

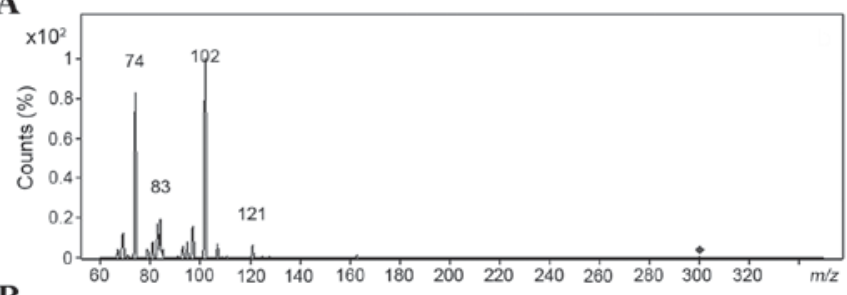

B

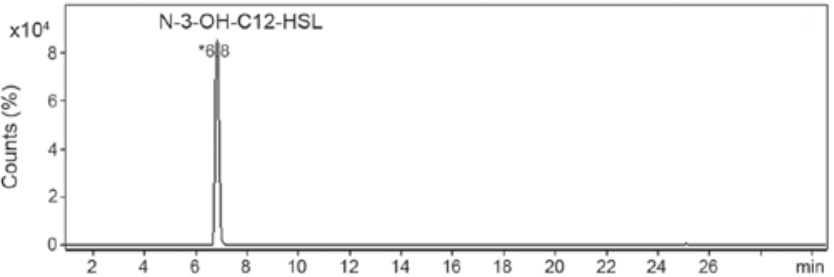

Figure 3. MS profiles of N-3-OH-C 12 -HSL. (A) MS2 spectrum of $\mathrm{N}-3-\mathrm{OH}-\mathrm{C}_{12}-\mathrm{HSL}(\mathrm{m} / \mathrm{z}, 300)$. (B) Secondary ion chromatogram of $\mathrm{N}-3-\mathrm{OH}-\mathrm{C}_{12}-\mathrm{HSL}$ derived from Acinetobacter baumannii strain S obtained using high-performance liquid chromatography and tandem quadrupole MS ( $m / z, 300 \geq m / z, 102)$. MS, mass spectrometry; $m / z$, mass-to-charge ratio; $\mathrm{N}-3-\mathrm{OH}-\mathrm{C}_{12}$-HSL, N-3-hydroxy-dodecanoyl-homoserine lactone.

Activity of mutant AHL. AHLs were isolated from the supernatant of AbS and AbS-M cultures incubated for $8 \mathrm{~h}$ at $37^{\circ} \mathrm{C}$ and the activity levels were analysed. AHL activity was significantly lower in AbS-M (12.67 \pm 1.53 Miller units) compared with wild-type AbS $(255.67 \pm 16.01$ Miller units $)$ $(\mathrm{P}<0.01 ;$ Fig. 5). 
<smiles>CCCCCC(O)CC(=O)NC1CCOC1=O</smiles>

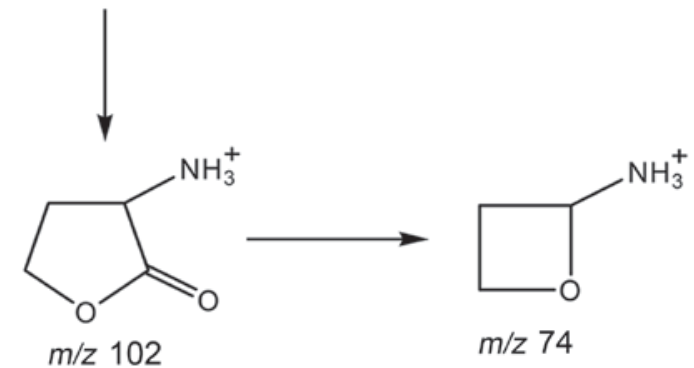

Figure 4. Major fragmentation pathway of N-3-hydroxy-dodecanoylhomoserine lactone. $\mathrm{m} / \mathrm{z}$, mass-to-charge ratio.

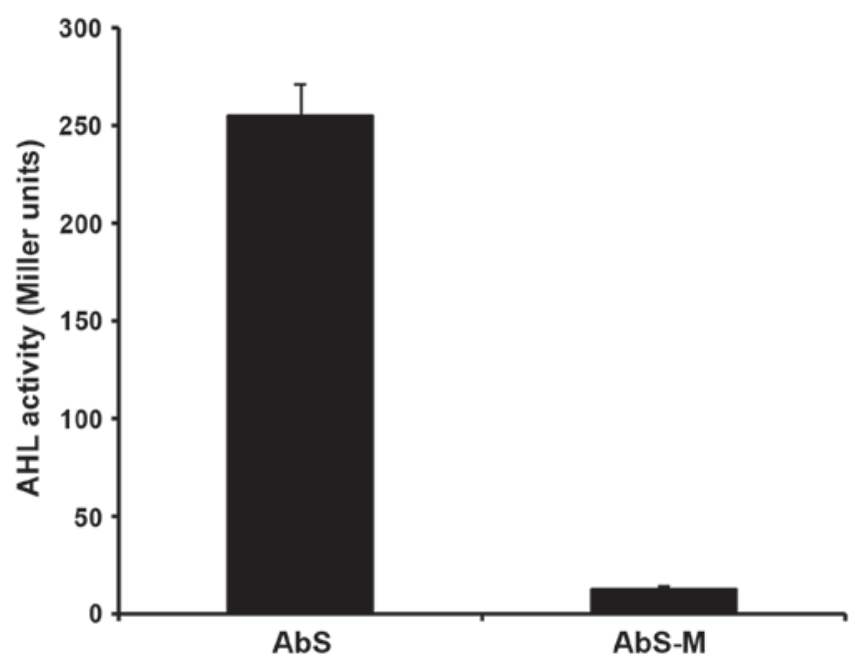

Figure 5. Activity of AHLs derived from AbS and AbS-M. The activity of AHLs derived from AbS-M (12.67 \pm 1.53$)$ was significantly lower compared with AHLs derived from wild-type AbS $(255.67 \pm 16.01)(\mathrm{P}<0.01)$. AHL, $\mathrm{N}$-acyl homoserine lactones; AbS, Acinetobacter baumannii strain S; AbS-M, AbS mutant.

Antibiotic sensitivity of $A b S, A b S-M$ and $A b S-M+H S L$. AbS was sensitive to amikacin, cefuroxime, ceftazidime, imipenem, gentamicin, ciprofloxacin, sulfamethoxazole/trimethoprim, sulperazone, tazocin, cefepime, panipenem, meropenem, ampicillin, Unasyn (which is a combination of ampicillin and sulbactam) and piperacillin. Then the MIC of AbS, AbS-M and AbS-M + HSL cultures to meropenem, piperacillin, ceftazidime, ciprofloxacin, sulfamethoxazole/trimethoprim and minocycline was assessed (Table II). The MICs of meropenem and piperacillin against AbS-M (0.25 and $1 \mu \mathrm{g} / \mathrm{ml}$, respectively) were lower than the MICs of these antibiotics against wild-type $\mathrm{AbS}(0.5$ and $2 \mu \mathrm{g} / \mathrm{ml}$, respectively). However, the addition of HSL to the AbS-M culture raised the MICs of meropenem and piperacillin to similar levels as wild-type $\mathrm{AbS}(0.5$ and $2 \mu \mathrm{g} / \mathrm{ml}$, respectively). By contrast, the MICs of ceftazidime, ciprofloxacin, sulfamethoxazole/trimethoprim and minocycline were similar for AbS, AbS-M and AbS-M + HSL.
Expression of drug-resistance genes in $A b S-U, A b S, A b S-M$ and $A b S-M+H S L$ treated with meropenem for $24 \mathrm{~h}$. AbS, AbS-M and AbS-M + HSL were cultured for $24 \mathrm{~h}$ in LB medium supplemented with meropenem $(0.125 \mu \mathrm{g} / \mathrm{ml})$, and $\mathrm{AbS}$ untreated with meropenem (AbS-U) was additionally cultured. The mRNA expression levels of drug-resistance genes were assessed by qPCR (Table III). Meropenem treatment increased the expression of $O X A-51, A m p C$, AdeA and $A d e B$ in all three bacterial cultures. The mRNA expression levels of these four genes were significantly lower in AbS-M compared with wild-type AbS; however, supplementation of AbS-M cultures with N-3-OH- $\mathrm{C}_{12}$-HSL increased the mRNA expression of these four drug-resistance genes to higher levels compared with wild-type $\mathrm{AbS}$ and untreated AbS-M. The expression of $O X A-23, I M P-4, V I M-2$ and AdeC could not be detected in any of the three strains.

\section{Discussion}

Quorum sensing affects bacterial biofilm formation $(27,28)$, antibacterial drug sensitivity (29) and bacterial virulence (30), suggesting that inhibition of this system may be a useful therapeutic strategy in combating the emergence of antibiotic-resistant strains of pathogenic bacteria. The present study aimed to contribute to the growing body of literature on AHLs produced by clinical isolates of A. baumannii.

The present study found that although the activity of AHLs produced by $\mathrm{AbS}$ was positively correlated with bacterial density in the log phase of growth, AHL activity reduced as growth plateaued; this trend has been previously reported for other bacteria $(31,32)$. N-(3-oxohexanoyl)-L-HSL produced by Erwinia carotovora was revealed to be unstable at $\mathrm{pH}>7-8$, which is the $\mathrm{pH}$ of the stationary phase of bacterial growth (40). Another study demonstrated that, during growth plateauing, A. tumefaciens produces abundant levels of acyl-homoserine lactonases, which reduce AHL activity (32). Thus, AHL activity seems to be regulated by the growth rate, which allows bacteria to respond to their changing density.

In the present study, HPLC-MS with TQ and Q-TOF was used to successfully identify AHLs. This method is advantageous because it does not depend on biosensor sensitivity and reference substances, and thus may be preferable to the conventional methods used for AHL identification, which combine thin-layer chromatography with biosensors.

AHLs produced by A. baumannii have been proposed to vary depending on culture conditions (41). One previous study identified 3-OH-C $\mathrm{C}_{12}$-HSL and other AHLs of unknown structure in cultures of $A$. baumannii strain M2 (38), whereas another study identified $\mathrm{C}_{6}$-HSL and $\mathrm{C}_{8}$-HSL in cultures of A. baumannii strain 4KT (15). Furthermore, $P$. aeruginosa infections in patients with cystic fibrosis have been reported to produce different AHLs in vivo and in vitro (42). Thus, the AHL identified in the present study may differ from those identified previously from A. baumannii, owing to the particular strain and culture conditions used. Additional experiments are required to identify the range of AHLs produced by this organism.

The present study established an AHL-deficient AbS mutant that was used to determine whether AHLs affected antibacterial drug sensitivity of AbS. Antibacterial drug-sensitivity assays 
Table II. Antibiotic sensitivity.

\begin{tabular}{lccc}
\hline & \multicolumn{3}{c}{$\begin{array}{c}\text { Minimum inhibitory } \\
\text { concentration }(\mu \mathrm{g} / \mathrm{ml})\end{array}$} \\
\cline { 2 - 4 } Antibiotic & AbS & AbS-M & AbS-M + HSL \\
\hline Meropenem & 0.5 & 0.25 & 0.5 \\
Piperacillin & 2.0 & 1.0 & 2.0 \\
Ceftazidime & 0.25 & 0.25 & 0.25 \\
Ciprofloxacin & 0.5 & 0.5 & 0.5 \\
Sulfamethoxazole/ & $0.25 / 4.75$ & $0.25 / 4.75$ & $0.25 / 4.75$ \\
trimethoprim & & & 0.5 \\
Minocycline & 0.5 & 0.5 & 0.5 \\
\hline
\end{tabular}

Abs, Acinetobacter baumannii strain S; AbS-M, AbS mutant; HSL, homoserine lactone.

Table III. mRNA expression levels of multidrug-resistance genes in meropenem-treated cultures or untreated cultures.

\begin{tabular}{lcccc}
\hline Gene & AbS-U & AbS & AbS-M & $\begin{array}{c}\text { AbS-M }+ \\
\text { HSL }\end{array}$ \\
\hline OXA-51 & $0.13 \pm 0.02$ & $1.09 \pm 0.13$ & $0.68 \pm 0.04^{\mathrm{a}}$ & $1.74 \pm 0.04$ \\
AmpC & $0.12 \pm 0.03$ & $0.94 \pm 0.11$ & $0.60 \pm 0.04^{\mathrm{a}}$ & $1.55 \pm 0.04$ \\
OXA-23 & $\mathrm{ND}$ & $\mathrm{ND}$ & $\mathrm{ND}$ & $\mathrm{ND}$ \\
IMP-4 & $\mathrm{ND}$ & $\mathrm{ND}$ & $\mathrm{ND}$ & $\mathrm{ND}$ \\
VIM-2 & $\mathrm{ND}$ & $\mathrm{ND}$ & $\mathrm{ND}$ & $\mathrm{ND}$ \\
AdeA & $0.08 \pm 0.04$ & $1.17 \pm 0.17$ & $0.59 \pm 0.08^{\mathrm{a}}$ & $1.66 \pm 0.25$ \\
AdeB & $0.09 \pm 0.08$ & $1.08 \pm 0.16$ & $0.51 \pm 0.09^{\mathrm{a}}$ & $1.31 \pm 0.11$ \\
AdeC & $\mathrm{ND}$ & $\mathrm{ND}$ & $\mathrm{ND}$ & $\mathrm{ND}$ \\
\hline
\end{tabular}

${ }^{\mathrm{a}} \mathrm{P}<0.01$ vs. Abs and AbS-M + AHLs. All data presented as the mean \pm standard deviation. AbS-U, Acinetobacter baumannii strain S untreated; AbS, Acinetobacter baumannii strain S; Abs-M, AbS mutant; HSL, homoserine lactone; ND, not detected; $O X A$, oxacillinase; AmpC, AmpC type $\beta$-lactamase; IMP, IMP type metallo- $\beta$-lactamase; VIM, verona integron-mediated metallo- $\beta$-lactamase; Ade, Acinetobacter drug efflux.

revealed that the MICs of meropenem and piperacillin were lower in AbS-M compared with wild-type AbS; however, the MICs returned to wild-type AbS levels when AbS-M cultures were treated HSL. Although this AHL-mediated increase in MICs was not substantial, this finding is promising in that it confirms the association between AHLs and antibiotic resistance in A. baumannii.

A previous report regarding the influence of AHLs on bacterial drug resistance mainly focused on their influence on biofilm formation (9). Previous studies have also described multiple mechanisms of drug resistance in A. baumannii, including the production of $\beta$-lactamases (43), which can be divided into four categories: Extended spectrum $\beta$-lactamases (44-46), metallo- $\beta$-lactamases $(47,48)$, AmpC enzyme (49) and oxacillinases $(50,51)$. However, the present study sought to determine the influence of AHLs on the expression of drug-resistance genes and revealed that in the presence of meropenem $\mathrm{AbS}$ expressed $O X A-51$ and $A m p C$, but not $O X A-23, I M P-4$, or $V I M-2$. OXA-51 was previously demonstrated to be strongly expressed in Acinetobacter spp. and may be the main drug-resistance gene $(52,53)$, whereas $A m p C$ is often found in A. baumannii strains from China $(54,55)$. The present study found that the mRNA expression levels of OXA-51 and AmpC were significantly lower in AbS-M compared with wild-type $\mathrm{AbS}$, but the levels recovered upon supplementation of the AbS-M culture with an AHL extract. These results indicate that AHLs may strengthen drug resistance by moderating the expression of drug-resistance genes.

In addition to producing $\beta$-lactamases, $A$. baumannii expresses efflux pump genes $A d e A, A d e B$ and $A d e C$, which confer resistance to $\beta$-lactam antibiotics, aminoglycosides, erythromycins, quinolones, tetracyclines, chloramphenicol and trimethoprim (43,56-62). The present study found that $A d e A$ and $A d e B$ were expressed by $\mathrm{AbS}$ in the presence of meropenem. It was not unexpected that $A d e C$ was not detected, since this gene is not essential for efflux pump activity (59). The mRNA expression levels of $A d e A$ and $A d e B$ were significantly lower in AbS-M than in wild-type AbS, and the expression of both AdeA and $A d e B$ was recovered with AHL supplementation. Results from the present study indicated that AbS AHLs promote the expression of $O X A-51, A m p C$, AdeA and AdeB in the presence of meropenem, suggesting that $\mathrm{AbS}$ produces AHLs to enhance antibiotic resistance. Furthermore, upregulation of $A d e B$ expression has been reported to be associated with the emergence of pan-resistant $A$. baumannii (57). Thus, AHLs may promote the emergence of meropenem-induced multidrug- and pan-resistance.

The present study has some limitations that should be noted. Although a mutant strain AbS was designed to be deficient in AHL, subsequent experiments with this mutant may have been influenced by the presence of abaI homologues; AbaI is similar to the LuxI family of autoinducer synthases (37). In addition, it is well known that AHLs can be degraded by $\mathrm{N}$-acylhomoserine lactone-lactonase (32). Therefore, we cannot rule out the possibility of AHL degradation due to lactonolysis. Lastly, the present study did not determine whether the mutation in AbS-M specifically reduces the transcription of $a b a I$ or whether it causes a generalized reduction in transcription.

In Gram-negative bacteria, AHL receptor systems include the cytoplasmic LuxR receptor and the transmembrane LuxN receptor (19). Inactivation of suppressor of division inhibition (SdiA), a bacterial homolog of LuxR, hampers the expression of the efflux pump drug-resistance genes $a c r A$ and $a c r B$, which are responsible for bacterial multidrug resistance, and AHLs may interact with SdiA to enhance the expression of $a c r A$ and acrB (63). Similar systems may exist in A. baumannii, and the interaction of AHLs with such systems may be able to induce the expression of drug-resistance genes. However, the MIC of the antibiotics ceftazidime, ciprofloxacin, sulfamethoxazole/trimethoprim and minocycline did not differ between the presence and absence of AHLs, suggesting that drug-resistant phenotypes may be produced by a diverse range of factors and genes. Conversely, exposure to meropenem for $24 \mathrm{~h}$ was perhaps insufficient to induce significant phenotypic alterations, and additional experiments are required to rule out longer-term 
changes to genes encoding resistance to these antibiotics. However, results from the present study are notable, since to the best of our knowledge no previous study has addressed the mechanisms underlying the influence of AbS AHLs on the expression of drug-resistance genes.

In the present study, the quorum-sensing system of $\mathrm{AbS}$ was demonstrated to involve N-3-OH- $\mathrm{C}_{12}-\mathrm{HSL}$, which induced the expression of drug-resistance genes $O X A-51, A m p C$, AdeA and $A d e B$ in the presence of meropenem. Loss of AHL production in $\mathrm{AbS}-\mathrm{M}$ resulted in reduced mRNA expression of these four drug-resistance genes, while treatment with $\mathrm{N}-3-\mathrm{OH}-\mathrm{C}_{12}-\mathrm{HSL}$ restored their expression. Thus, AHL-mediated induction of Ade $A$ and $A d e B$ expression could in turn lead to multidrug resistance in $A$. baumannii. These results highlight a new direction for the development of drugs targeting A. baumannii, particularly pan-resistant strains.

\section{Acknowledgements}

The authors thank Professor Jun Zhu (College of Life Sciences, Nanjing Agricultural University, Nanjing, China) for his kind gift of A. tumefaciens KYC55 and Professor Philip N. Rather (Department of Microbiology and Immunology, Emory University School of Medicine, Atlanta, GA, USA) for his kind gift of the pKNG101.abaI::Km plasmid. The authors are also grateful to the Shanghai Ninth Peoples Hospital, Shanghai Jiaotong University School of Medicine, Shanghai Research Institute of Stomatology and Shanghai Key Laboratory of Stomatology (Shanghai, China) for experimental support.

\section{References}

1. Dou Y,Zhang Q and Liao ZJ: Investigation on the drug resistance of Pseudomonas aeruginosa in our burn ward in the past 11 years. Zhonghua Shao Shang Za Zhi 20: 6-9, 2004 (In Chinese).

2. Dou Y, Zhang X, Zhang Q and Shi Y: Analysis of the drug-resistance of Pseudomonas aeruginosa and the use of antibiotics in burn wards. Zhonghua Shao Shang Za Zhi 27: 109-113, 2011 (In Chinese).

3. Essayagh T, Zohoun A, Essayagh M, Elameri A, Zouhdi M, Ihrai $\mathrm{H}$ and Elhamzaoui S: Bacterial epidemiology in the burns unit at military teaching hospital Mohamed V of Rabat. Ann Biol Clin (Paris) 69: 71-76, 2011 (In French).

4. Chong SJ, Ahmed S, Tay JM, Song C and Tan TT: 5 year analysis of bacteriology culture in a tropical burns ICU. Burns 37: 1349-1353, 2011.

5. Glik J, Kawecki M, Gázdzik T and Nowak M: The impact of the types of microorganisms isolated from blood and wounds on the results of treatment in burn patients with sepsis. Pol Przegl Chir 84: 6-16, 2012.

6. Dijkshoorn L, Nemec A and Seifert H: An increasing threat in hospitals: Multidrug-resistant Acinetobacter baumannii. Nat Rev Microbiol 5: 939-951,2007.

7. Lin MF and Lan CY: Antimicrobial resistance in Acinetobacter baumannii: From bench to bedside. World J Clin Cases 2: 787-814, 2014.

8. Simor AE, Lee M, Vearncombe M, Jones-Paul L, Barry C, Gomez M, Fish JS, Cartotto RC, Palmer R and Louie M: An outbreak due to multiresistant Acinetobacter baumannii in a burn unit: Risk factors for acquisition and management. Infect Control Hosp Epidemiol 23: 261-267, 2002.

9. Li YH and Tian X: Quorum sensing and bacterial social interactions in biofilms. Sensors (Basel) 12: 2519-2538, 2012.

10. Zan J, Heindl JE, Liu Y, Fuqua C and Hill RT: The CckA-ChpT-CtrA phosphorelay system is regulated by quorum sensing and controls flagellar motility in the marine sponge symbiont Ruegeria sp. KLH11. PLoS One 8: e66346, 2013.
11. Smith RS, Harris SG, Phipps R and Iglewski B: The Pseudomonas aeruginosa quorum-sensing molecule $\mathrm{N}$-(3-oxododecanoyl)homoserine lactone contributes to virulence and induces inflammation in vivo. J Bacteriol 184: 1132-1139, 2002.

12. Antunes LC, Ferreira RB, Buckner MM and Finlay BB: Quorum sensing in bacterial virulence. Microbiology 156: 2271-2282, 2010.

13. Bhargava N, Sharma P and Capalash N: Quorum sensing in Acinetobacter: An emerging pathogen. Crit Rev Microbiol 36: 349-360, 2010

14. Miller MB and Bassler BL: Quorum sensing in bacteria. Annu Rev Microbiol 55: 165-199, 2001.

15. Chan KG, Cheng HJ, Chen JW, Yin WF and Ngeow YF: Tandem mass spectrometry detection of quorum sensing activity in multidrug resistant clinical isolate Acinetobacter baumannii. ScientificWorldJournal 2014: 891041, 2014.

16. Stacy DM, Welsh MA, Rather PN and Blackwell HE: Attenuation of quorum sensing in the pathogen Acinetobacter baumannii using non-native N-Acyl homoserine lactones. ACS Chem Biol 7: 1719-1728, 2012.

17. Chow JY, Yang Y, Tay SB, Chua KL and Yew WS: Disruption of biofilm formation by the human pathogen Acinetobacter baumannii using engineered quorum-quenching lactonases. Antimicrob Agents Chemother 58: 1802-1805, 2014.

18. Roy V, Adams BL and Bentley WE: Developing next generation antimicrobials by intercepting AI-2 mediated quorum sensing. Enzyme Microb Technol 49: 113-123, 2011.

19. Chen G, Swem LR, Swem DL, Stauff DL, O'Loughlin CT, Jeffrey PD, Bassler BL and Hughson FM: A strategy for antagonizing quorum sensing. Mol Cell 42: 199-209, 2011.

20. Kalia VC: Quorum sensing inhibitors: An overview. Biotechnol Adv 31: 224-245, 2013.

21. Berger M, Neumann A, Schulz S, Simon M and Brinkhoff T: Tropodithietic acid production in Phaeobacter gallaeciensis is regulated by $\mathrm{N}$-acyl homoserine lactone-mediated quorum sensing. J Bacteriol 193: 6576-6585, 2011.

22. Churchill ME and Chen L: Structural basis of acyl-homoserine lactone-dependent signaling. Chem Rev 111: 68-85, 2011.

23. Van Mooy BA, Hmelo LR, Sofen LE, Campagna SR, May AL, Dyhrman ST, Heithoff A, Webb EA, Momper L and Mincer TJ: Quorum sensing control of phosphorus acquisition in Trichodesmium consortia. ISME J 6: 422-429, 2012.

24. Bruhn JB, Christensen AB, Flodgaard LR, Nielsen KF, Larsen TO, Givskov M and Gram L: Presence of acylated homoserine lactones (AHLs) and AHL-producing bacteria in meat and potential role of AHL in spoilage of meat. Appl Environ Microbiol 70: 4293-4302, 2004.

25. Gould TA, Herman J, Krank J, Murphy RC and Churchill ME: Specificity of acyl-homoserine lactone synthases examined by mass spectrometry. J Bacteriol 188: 773-783, 2006.

26. Wayne P: Clinical and Laboratory Standards Institute: Methods for Dilution Antimicrobial Susceptibility Tests for bacteria that grow aerobically. Approved Standard, seventh edition, M7-A7, CLSI, 2006.

27. Cady NC, McKean KA, Behnke J, Kubec R, Mosier AP, Kasper SH, Burz DS and Musah RA: Inhibition of biofilm formation, quorum sensing and infection in Pseudomonas aeruginosa by natural products-inspired organosulfur compounds. PLoS One 7: e38492, 2012.

28. Jakobsen TH, Bragason SK, Phipps RK, Christensen LD, van Gennip M, Alhede M, Skindersoe M, Larsen TO, Høiby N, Bjarnsholt T and Givskov M: Food as a source for quorum sensing inhibitors: Iberin from horseradish revealed as a quorum sensing inhibitor of Pseudomonas aeruginosa. Appl Environ Microbiol 78: 2410-2421, 2012.

29. Brackman G, Cos P, Maes L, Nelis HJ and Coenye T: Quorum sensing inhibitors increase the susceptibility of bacterial biofilms to antibiotics in vitro and in vivo. Antimicrob Agents Chemother 55: 2655-2661, 2011.

30. Koh KH and Tham FY: Screening of traditional Chinese medicinal plants for quorum-sensing inhibitors activity. J Microbiol Immunol Infect 44: 144-148, 2011.

31. Byers JT, Lucas C, Salmond GP and Welch M: Nonenzymatic turnover of an Erwinia carotovora quorum-sensing signaling molecule. J Bacteriol 184: 1163-1171, 2002.

32. Zhang HB, Wang LH and Zhang LH: Genetic control of quorum-sensing signal turnover in Agrobacterium tumefaciens. Proc Natl Acad Sci USA 99: 4638-4643, 2002. 
33. Ortori CA, Atkinson S, Chhabra SR, Camara M, Williams P and Barrett DA: Comprehensive profiling of $\mathrm{N}$-acylhomoserine lactones produced by Yersinia pseudotuberculosis using liquid chromatography coupled to hybrid quadrupole-linear ion trap mass spectrometry. Anal Bioanal Chem 387: 497-511, 2007.

34. Shaw PD, Ping G, Daly SL, Cha C, Cronan JE Jr, Rinehart KL and Farrand SK: Detecting and characterizing N-acyl-homoserine lactone signal molecules by thin-layer chromatography. Proc Natl Acad Sci USA 94: 6036-6041, 1997.

35. Cha C, Gao P, Chen YC, Shaw PD and Farrand SK: Production of acyl-homoserine lactone quorum-sensing signals by gram-negative plant-associated bacteria. Mol Plant Microbe Interact 11: 1119-1129, 1998

36. Clinical and Laboratory Standards Institute. Performance standards for antimicrobial susceptibility testing: Twenty-forth Informational Supplement M100-S24. CLSI, Wayne, PA, USA, 2014.

37. Zhu J, Chai Y, Zhong Z, Li S and Winans SC: Agrobacterium bioassay strain for ultrasensitive detection of $\mathrm{N}$-acylhomoserine lactone-type quorum-sensing molecules: Detection of autoinducers in Mesorhizobium huakuii. Appl Environ Microbiol 69: 6949-6953, 2003.

38. Niu C, Clemmer KM, Bonomo RA and Rather PN: Isolation and characterization of an autoinducer synthase from Acinetobacter baumannii. J Bacteriol 190: 3386-3392, 2008.

39. Livak KJ and Schmittgen TD: Analysis of relative gene expression data using real-time quantitative PCR and the 2(-Delta Delta C(T)) Method. Methods 25: 402-408, 2001.

40. Byers JT, Lucas C and Salmond GP and Welch M: Nonezymatic turnover of an Erwinia carotovora quorum-sensing signal molecule. J Bacteriol 184: 1163-1171, 2002.

41. González RH, Nusblat A and Nudel BC: Detection and characterization of quorum sensing signal molecules in Acinetobacter strains. Microbiol Res 155: 271-277, 2001.

42. Middleton B, Rodgers HC, Cámara M, Knox AJ, Williams P and Hardman A: Direct detection of $\mathrm{N}$-acylhomoserine lactones in cystic fibrosis sputum. FEMS Microbiol Lett 207: 1-7, 2002.

43. Peleg AY, Seifert $H$ and Paterson DL: Acinetobacter baumannii: Emergence of a successful pathogen. Clin Microbiol Rev 21: $538-582,2008$

44. Poirel L, Mugnier PD, Toleman MA, Walsh TR, Rapoport MJ, Petroni A and Nordmann P: ISCR2, another vehicle for bla(VEB) gene acquisition. Antimicrob Agents Chemother 53: 4940-4943, 2009.

45. Naas T, Bogaerts P, Bauraing C, Degheldre Y, Glupczynski Y and Nordmann P: Emergence of PER and VEB extended-spectrum beta-lactamases in Acinetobacter baumannii in Belgium J Antimicrob Chemother 58: 178-182, 2006.

46. Nagano N, Nagano Y, Cordevant C, Shibata N and Arakawa Y: Nosocomial transmission of CTX-M-2 beta-lactamase-producing Acinetobacter baumannii in a neurosurgery ward. J Clin Microbiol 42: 3978-3984, 2004.

47. Yum JH, Yi K, Lee H, Yong D, Lee K, Kim JM, Rossolini GM and Chong Y: Molecular characterization of metallo-beta-lactamase-producing Acinetobacter baumannii and Acinetobacter genomospecies 3 from Korea: Identification of two new integrons carrying the bla(VIM-2) gene cassettes. J Antimicrob Chemother 49: 837-840, 2002

48. Houang ET, Chu YW, Lo WS, Chu KY and Cheng AF: Epidemiology of rifampin ADP-ribosyltransferase (arr-2) and metallo-btea-lactamase $\left(\right.$ bla $\left._{\text {IMP-4 }}\right)$ gene cassettes in class 1 integrons in Acinetobacter strains isolated from blood cultures in 1997 to 2000. Antimicrob Agents Chemother 47: 1382-1390, 2003.

49. Tian GB, Adams-Haduch JM, Taracila M, Bonomo RA, Wang HN and Doi Y: Extended-spectrum AmpC cephalosporinase in Acinetobacter baumannii: ADC-56 confers resistance to cefepime. Antimicrob Agents Chemother 55: 4922-4925, 2011.
50. Mendes RE, Bell JM, Turnidge JD, Castanheira M and Jones RN Emergence and widespread dissemination of OXA-23, -24/40 and -58 carbapenemases among Acinetobacter spp. in Asia-Pacific nations: Report from the SENTRY surveillance program. J Antimicrob Chemother 63: 55-59, 2009.

51. Zong Z, Lu X, Valenzuela JK, Partridge SR and Iredell J: An outbreak of carbapenem-resistant Acinetobacter baumannii producing OXA-23 carbapenemase in western China. Int J Antimicrob Agents 31: 50-54, 2008

52. Feizabadi MM, Fathollahzadeh B, Taherikalani M, Rasoolinejad M, Sadeghifard N, Aligholi M, Soroush S and Mohammadi-Yegane S: Antimicrobial susceptibility patterns and distribution of blaOXA genes among Acinetobacter spp. isolated from patients at Tehran hospitals. Jpn J Infect Dis 61: 274-278, 2008

53. Wang H, Guo P, Sun H, Wang H, Yang Q, Chen M, Xu Y and Zhu Y: Molecular epidemiology of clinical isolates of carbapenem-resistant Acinetobacter spp. from Chinese hospitals. Antimicrob Agents Chemother 51: 4022-4028, 2007.

54. Wei LH, Zhang J, Deng JJ, Zou FM, Liu G and Si XQ: The isolation of Acinetobacter strain from burn wound and the analysis of its antibiotic resistance. Zhonghua Shao Shang Za Zhi 20: 17-19, 2004 (In Chinese).

55. Wang H,Liu YM,ChenMJ,SunHL,XieXLandXuYC:Mechanism of carbapenems resistance in Acinetobacter baumannii.Zhongguo Yi Xue Ke Xue Yuan Xue Bao 25: 567-572, 2003 (In Chinese).

56. Héritier C, Poirel L, Lambert T and Nordmann P: Contribution of acquired carbapenem-hydrolyzing oxacillinases to carbapenem resistance in Acinetobacter baumannii. Antimicrob Agents Chemother 49: 3198-3202, 2005.

57. Higgins PG, Wisplinghoff H, Stefanik D and Seifert H: Selection of topoisomerase mutations and overexpression of adeB mRNA transcripts during an outbreak of Acinetobacter baumannii. J Antimicrob Chemother 54: 821-823, 2004.

58. Magnet S, Courvalin P and Lambert T: Resistance-nodulation-cell division-type efflux pump involved in aminoglycoside resistance in Acinetobacter baumannii strain BM4454. Antimicrob Agents Chemother 45: 3375-3380, 2001.

59. Marchand I, Damier-Piolle L, Courvalin P and Lambert T: Expression of the RND-type efflux pump AdeABC in Acinetobacter baumannii is regulated by the AdeRS two-component system. Antimicrob Agents Chemother 48: 3298-3304, 2004.

60. Nemec A, Maixnerova M, van der Reijden TJ, van den Broek PJ and Dijkshoorn L: Relationship between the AdeABC efflux system gene content, netilmicin susceptibility and multidrug resistance in a genotypically diverse collection of Acinetobacter baumannii strains. J Antimicrob Chemother 60: 483-489, 2007.

61. Peleg AY, Adams J and Paterson DL: Tigecycline efflux as a mechanism for nonsusceptibility in Acinetobacter baumannii. Antimicrob Agents Chemother 51: 2065-2069, 2007.

62. Ruzin A, Keeney D and Bradford PA: AdeABC multidrug efflux pump is associated with decreased susceptibility to tigecycline in Acinetobacter calcoaceticus-Acinetobacter baumannii complex. J Antimicrob Chemother 59: 1001-1004, 2007.

63. Rahmati S, Yang S, Davidson AL and Zechiedrich EL: Control of the AcrAB multidrug efflux pump by quorum-sensing regulator SdiA. Mol Microbiol 43: 677-685, 2002. 